\title{
Pan-Genotypic Hepatitis C Treatment with Glecaprevir and Pibrentasvir for 8 Weeks Resulted in Improved Cardiovascular and Metabolic Outcomes and Stable Renal Function: A Post-Hoc Analysis of Phase 3 Clinical Trials
}

\author{
Tram T. Tran · Darshan Mehta · Federico Mensa - Caroline Park • \\ Yanjun Bao • Yuri Sanchez Gonzalez
}

Received: August 21, 2018 / Published online: October 27, 2018

(C) The Author(s) 2018

\begin{abstract}
Introduction: Chronic hepatitis C (CHC) infection is associated with extrahepatic manifestations (EHMs) which can affect renal, cardiovascular and other comorbidities. The effect of $\mathrm{CHC}$ treatment with short-duration regimens on these EHMs is not well defined. Hence, we examined longitudinal estimated glomerular filtration rate (eGFR), triglycerides and glucose values to assess the impact of short-duration $\mathrm{CHC}$ therapy on renal, cardiovascular and metabolic diseases, respectively.
\end{abstract}

Enhanced digital features To view enhanced digital features for this article go to https://doi.org/10.6084/ m9.figshare.7211873.

Electronic supplementary material The online version of this article (https://doi.org/10.1007/s40121018-0218-x) contains supplementary material, which is available to authorized users.

\section{T. T. Tran}

Liver Disease and Transplant Center, Cedars-Sinai Medical Center, Los Angeles, CA, USA

D. Mehta

Schaeffer Center for Health Policy and Economics, University of Southern California, Los Angeles, CA, USA

D. Mehta · F. Mensa - C. Park - Y. Bao ·

Y. Sanchez Gonzalez $(\bowtie)$

AbbVie Inc., North Chicago, IL, USA

e-mail: yuri.sanchezgonzalez@abbvie.com
Methods: We conducted analyses of all patients without cirrhosis treated with glecaprevir and pibrentasvir $(\mathrm{G} / \mathrm{P})$ for 8 weeks in two phase 3 clinical trials. In addition, one phase 3 trial was carried out to explore the effects of treatment on renal EHMs in patients with advanced renal impairment at baseline. As a sensitivity analysis, we included all CHC patients treated with G/P for 8 or 12 weeks enrolled across five phase 3 trials. Adjusting for baseline demographics and clinical properties via mixed regression models enabled evaluation of changes in EHMs through end of treatment.

Results: G/P treatment for 8 weeks resulted in statistically significant declines in triglycerides $(-28.6 \mathrm{mg} / \mathrm{dl})$ and glucose $(-11.2 \mathrm{mg} / \mathrm{dl})$, while there was no statistically significant decline in eGFR. Biomarker improvements were greatest among patients with elevated triglycerides and elevated glucose at baseline. Similar effects were observed across all patients treated with G/P for 8 or 12 weeks.

Conclusion: Short-duration treatment with G/P resulted in stable renal function and improvements in cardiovascular and metabolic EHM markers, especially in patients with severe EHMs at baseline.

Funding: AbbVie Inc.

Keywords: Extrahepatic manifestations; Glecaprevir; Glucose; Hepatitis C; Pibrentasvir 


\section{INTRODUCTION}

Approximately 71 million people are living with chronic hepatitis $C$ virus infection (HCV) worldwide [1]. Patients with HCV have an increased risk of long-term liver complications, such as cirrhosis, liver failure, hepatocellular carcinoma, and liver-related mortality [2]. Furthermore, $\mathrm{HCV}$ is associated with various extrahepatic manifestations (EHMs), including type 2 diabetes mellitus, insulin resistance, mixed cryoglobulinemia, non-Hodgkin's lymphoma (NHL), cardiovascular disease, chronic kidney disease (CKD), and cognitive impairment [3-9]. Although three-quarters of patients infected with HCV may have at least one EHM, this risk may not be recognized by many clinicians [4].

According to several studies, a sustained virologic response (SVR) with HCV antiviral therapy is associated with a decreased risk of hepatic complications [10-12]; however, few studies have assessed the effects of SVR on EHM outcomes [13-16]. A meta-analysis of data from 48 studies [17] demonstrated that, in patients with chronic HCV infection who were treated with INF-free antiviral therapy, SVR (vs. no SVR) was associated with reduced extrahepatic mortality, higher complete remission in patients with cryoglobulinemia vasculitis, and a higher objective response in those with malignant B cell lymphoproliferative diseases. Attainment of SVR was also associated with reduced insulin resistance and a protective effect on the incidence of diabetes. Furthermore, a study conducted in a US Veteran population concluded that the risk of EHMs was reduced after attainment of SVR, and initiation of treatment at early fibrosis stages might be required to reduce risk of certain EHMs (i.e., glomerulonephritis, NHL and stroke) [16].

For patients with HCV, the standard of care has evolved towards IFN-free therapies with direct-acting antiviral agents (DAAs) that are used for shorter time periods and have greater efficacy and better safety profiles [18]. In the era of these highly effective DAA regimens, studies have elucidated the clinical and economic burden of EHMs for patients with HCV. An analysis of registrational trials for ombitasvir/paritaprevir (identified by AbbVie and Enanta)/ritonavir and dasabuvir with or without ribavirin $(3 \mathrm{D} \pm$ RBV) resulted in improvement of cardiovascular and metabolic EHMs and no worsening of renal function among genotype $1 \mathrm{HCV}$ patients [19]. US-based retrospective studies suggest that $\mathrm{HCV}$-treated patients may have reduced risk of cardiovascular and cerebrovascular events [20], and that these clinical benefits may translate into medical cost savings of up to US $\$ 25,000$ in all-cause medical costs per patient per year [21].

Oral pan-genotypic DAA regimens have been approved [22], but their impact on EHMs is not well defined. Additionally, the demographic profile of treated patients has evolved over the years. As the majority of cirrhotic patients are prioritized and successfully treated, the treatment-eligible population in the future is more likely to be comprised of treatment-naïve and non-cirrhotic (TN NC) patients. Approval of the DAA regimen glecaprevir (identified by AbbVie and Enanta) and pibrentasvir (G/P) has made CHC treatment for 8 weeks a possibility for the TN NC patient population across all HCV genotypes [22]. While the effect of SVR on EHMs has been described for 12 weeks of treatment with $3 \mathrm{D} \pm \mathrm{RBV}$ [19], the effects of newer generation agents with shorter treatment duration, such as G/P, have not been established.

To address this evidence gap, we analyzed pooled data on patients treated for 8 weeks in two phase 3 clinical trials of $G / P$ to assess the impact of $\mathrm{CHC}$ treatment on renal, cardiovascular and metabolic EHMs, and the differential impact of treatment by baseline EHM disease severity. As a sensitivity analysis, we also analyzed pooled data of patients treated with $\mathrm{G} / \mathrm{P}$ for 8 or 12 weeks across five phase 3 clinical trials.

\section{METHODS}

EHMs were defined as non-liver-related conditions previously associated with HCV infection [23-27]. The study used non-fasting triglycerides, non-fasting glucose and estimated glomerular filtration rate (eGFR) as surrogate measures of cardiovascular, metabolic and renal 
EHMs, respectively. Concentrations of these biomarkers have been associated with risks of adverse outcomes (i.e., mortality, stroke, diabetes, CKD) [23-27].

To assess the impact of short-duration $\mathrm{CHC}$ treatment on renal, cardiovascular and metabolic EHMs, data on patients without cirrhosis treated with $G / P$ for 8 weeks were extracted from two phase 3 clinical trials (ENDURANCE-1 and ENDURANCE-3). To assess the differential effects of treatment according to baseline EHM disease severity, patients were further subdivided by baseline EHM severity level. Treatment history was also used to classify patients into treatment-naïve (TN) and treatment-experienced (TE) subgroups. For each studied biomarker, patients with a baseline value and at least one value post-baseline were included in the analysis. In addition, the EXPEDITION-4 trial was used to investigate the effects of treatment on renal EHMs in patients with severe baseline renal impairment (i.e., CKD stages 4 and 5). As a sensitivity analysis, we pooled data of patients with or without cirrhosis who received G/P for 8 or 12 weeks across five phase 3 clinical trials (ENDURANCE-1, ENDURANCE2, ENDURANCE-3, ENDURANCE-4 and EXPEDITION-1). Table S1 briefly explains the designs of these studies.

Baseline biomarker values were used to define EHM disease severity. For cardiovascular EHMs, non-fasting baseline triglyceride concentrations greater than or equal to $175 \mathrm{mg} / \mathrm{dl}$ were defined as elevated [28]. For metabolic EHMs, pre-diabetes was defined as non-fasting baseline glucose values of $140-200 \mathrm{mg} / \mathrm{dl}$, and diabetes was defined as non-fasting baseline glucose concentrations higher than $200 \mathrm{mg} / \mathrm{dl}$ [29], irrespective of any reported history of diabetes. For renal EHMs, CKD stages were defined according to Kidney Disease Improving Global Outcomes (KDIGO) guidelines as stage 1 $\left(\mathrm{eGFR} \geq 90 \mathrm{ml} / \mathrm{min} / 1.73 \mathrm{~m}^{2}\right)$, stage 2 (eGFR $\left.60-89 \mathrm{ml} / \mathrm{min} / 1.73 \mathrm{~m}^{2}\right)$, stage $3(30-59 \mathrm{ml} / \mathrm{min} /$ $\left.1.73 \mathrm{~m}^{2}\right)$, stage $4\left(\right.$ eGFR $\left.15-29 \mathrm{ml} / \mathrm{min} / 1.73 \mathrm{~m}^{2}\right)$, stage 5 (eGFR $<15 \mathrm{ml} / \mathrm{min} / 1.73 \mathrm{~m}^{2}$ or dialysisdependent) [30]. In the sensitivity analysis, baseline cirrhosis status and treatment history were used to classify patients into the following subgroups: TN NC, TN cirrhotic, TE NC, TE cirrhotic.

Mean changes from baseline were estimated at end of treatment and post-treatment week 4 for each EHM biomarker, with statistical significance assessed using $t$ tests. To meet the criteria for improvement in cardiovascular and metabolic EHMs, patients needed to have statistically significant decreases in triglycerides and glucose values, respectively. To meet the criteria for improvement in renal EHMs, patients needed to have a statistically significant increase in eGFR. The proportions of patients with elevated triglycerides, pre-diabetes and diabetes, and CKD stages 2 and 3 who had improvement in biomarker levels below defined thresholds were also assessed for each EHM by end of treatment, as well as the proportion of patients who had sustained control of EHMs at each follow-up time point. For metabolic and renal EHMs, proportions of patients who had clinically meaningful improvements $(\geq 10 \%)$ at each time point were also studied.

Longitudinal mixed models (MM) [31] were applied to measure treatment effects on each EHM biomarker. The regression model controlled for patient baseline biomarker values, demographics and clinical properties [i.e., age, gender, body mass index (BMI), fibrosis stage, genotype, presence of diabetes, $\mathrm{HCV}$ treatment history, viral load]. Because the analysis incorporated pooled data from a variety of trials, the model also controlled for patients' clinical trial enrollment. Using regression coefficients derived from the $\mathrm{MM}$, changes from baseline to various timepoints during and after treatment were estimated and plotted. In the pooled sensitivity analysis, MM analyses were conducted for subgroups defined by treatment history and cirrhosis status. In the following results, we report adjusted change from baseline at end of treatment as it represents a treatment completion milestone. The supporting tables and figures provide adjusted change from baseline at each time point until post-treatment week 4 .

This analysis was conducted based on biomarker data collected in previously conducted studies and did not involve any new studies with human or animal subjects performed by any of the authors. 


\section{RESULTS}

Table 1 provides the baseline characteristics for the primary sample of $505 \mathrm{NC}$ patients who received $G / P$ for 8 weeks. Across this study population, most patients were genotype 1 $(69.5 \%)$ and TN $(74.1 \%)$, with an average age of 49.7 years. With respect to clinical profile, $98.4 \%$ of patients achieved SVR, $14.9 \%$ had $\mathrm{BMI} \geq 30 \mathrm{~kg} / \mathrm{m}^{2}$ and $33.5 \%$ had HOMA$\mathrm{IR} \geq 2 \mathrm{mU} \mathrm{mmol} / \mathrm{l}^{2}$. Tables S2 and S3 provide baseline characteristics for the pooled sample of patients treated for 8 or 12 weeks by baseline EHM disease severity, treatment history and cirrhosis status, respectively (1554 patients in total).

Analysis of cardiovascular EHMs for patients who received G/P for 8 weeks showed a significant reduction of $-28.6 \mathrm{mg} / \mathrm{dl} \quad(p<0.0001$; $95 \% \mathrm{CI}-38.3 \mathrm{mg} / \mathrm{dl},-18.9 \mathrm{mg} / \mathrm{dl})$ in mean triglyceride levels at end of treatment as compared to baseline (Fig. 1a). Patients with elevated baseline triglycerides experienced the most pronounced improvement from baseline by end of treatment $(-60.4 \mathrm{mg} / \mathrm{dl} ; p<0.0001$; $95 \%$ CI $-78.5 \mathrm{mg} / \mathrm{dl},-42.2 \mathrm{mg} / \mathrm{dl}$ ) (Fig. 1a). In the subset of TN patients treated for 8 weeks, $\mathrm{G} / \mathrm{P}$ yielded a decrease of $17.7 \mathrm{mg} / \mathrm{dl}$ ( $p=0.0038 ; 95 \% \mathrm{CI}-28.7 \mathrm{mg} / \mathrm{dl},-5.5 \mathrm{mg} / \mathrm{dl})$ by end of treatment (Fig. 1b). TN patients with elevated baseline triglycerides experienced greater decreases during treatment $(-45.5 \mathrm{mg} /$ $\mathrm{dl} ; p<0.001 ; 95 \% \mathrm{CI}-59.8 \mathrm{mg} / \mathrm{dl},-31.3 \mathrm{mg} /$ dl) in comparison with TN patients with normal triglycerides $(11.3 \mathrm{mg} / \mathrm{dl}$ increase; $p=0.03 ; 95 \%$ CI $0.6 \mathrm{mg} / \mathrm{dl}, 22.1 \mathrm{mg} / \mathrm{dl}$, which did not result in levels over $175 \mathrm{mg} / \mathrm{dl}$ ) (Fig. 1b). Similar trends were observed in TE patients who received G/P for 8 weeks (see Table S4) and in all patients who received G/P for 8 or 12 weeks, regardless of treatment history and cirrhosis status (Figure S1; Table S5a). Furthermore, 61\% of patients treated for 8 weeks who had elevated triglycerides at baseline had triglyceride levels within the normal range by the end of treatment (Fig. 1c). Among the TN NC subgroup with elevated triglycerides at baseline, $71 \%$ had normal levels by the end of treatment.
Short-duration treatment with G/P also significantly improved metabolic EHMs: the adjusted mean glucose level at the end of treatment was significantly lower than the baseline level (mean adjusted decline of $-11.2 \mathrm{mg} / \mathrm{dl} ; p<0.0001 ; 95 \% \mathrm{CI}-16.5 \mathrm{mg} / \mathrm{dl}$; - $5.7 \mathrm{mg} / \mathrm{dl}$ ) (Fig. 2a). Patients with elevated glucose levels at baseline (i.e., with pre-diabetes or diabetes) exhibited a pronounced improvement in glucose levels by end of treatment $(-23.7 \mathrm{mg} / \mathrm{dl} ; p<0.0001 ; 95 \% \mathrm{CI}-34.2 \mathrm{mg} / \mathrm{dl}$, $13.2 \mathrm{mg} / \mathrm{dl}$ ) (Fig. 2a). In the subset of TN patients treated for 8 weeks, G/P resulted in a decline of $31.6 \mathrm{mg} / \mathrm{dl}$ by end of treatment (Fig. 2b; Table S6). Patients with pre-diabetes and diabetes had larger decreases in glucose levels during treatment than did patients with normal glucose levels (Fig. 2b). The subgroup of TN patients with pre-diabetes and diabetes had a decline of $\quad 23.3 \mathrm{mg} / \mathrm{dl} \quad(p<0.001 ; \quad 95 \% \quad$ CI - $30.1 \mathrm{mg} / \mathrm{dl}, \quad-16.6 \mathrm{mg} / \mathrm{dl})$ and $98.3 \mathrm{mg} / \mathrm{dl}$ $(p<0.0001 ; 95 \%$ CI $-109.7 \mathrm{mg} / \mathrm{dl},-87.1 \mathrm{mg} /$ $\mathrm{dl})$, respectively, and $\mathrm{TN}$ patients with normal glucose had no statistically significant change $(p=0.32 ; 95 \% \mathrm{CI}-1.7 \mathrm{mg} / \mathrm{dl}, 5.4 \mathrm{mg} / \mathrm{dl})$, which also did not result in levels over $100 \mathrm{mg} / \mathrm{dl}$ (Fig. 2a, b). A similar trend was observed in TE patients treated for 8 weeks (see Table S4) and in the pooled sample of patients treated for 8 or 12 weeks regardless of treatment history and cirrhosis status (Figure S2; Table S5b). Descriptive analysis showed $56 \%$ of patients with pre-diabetes or diabetes at baseline had glucose levels within normal range by end of treatment (Fig. 2c), and 65\% experienced improvements of at least $10 \%$. Among the TN NC subgroup with pre-diabetes or diabetes at baseline, $83 \%$ had normal glucose levels by the end of treatment or experienced improvements of at least 10\%.

G/P did not significantly affect renal function as patients had no statistically significant decline in eGFR from baseline at the end of 8 weeks of treatment (mean adjusted change of $2.1 \mathrm{ml} / \mathrm{min} / \mathrm{m}^{2} ; p=0.34 ; 95 \% \mathrm{CI}$ - $2.4 \mathrm{ml} / \mathrm{min} / \mathrm{m}^{2} ; 6.9 \mathrm{ml} / \mathrm{min} / \mathrm{m}^{2}$ ) (Fig. 3a). This was also observed in: (1) the subset of patients with stage 2 and 3 CKD (CKD stage 2: $1.4 \mathrm{ml} / \mathrm{min} / \mathrm{m}^{2} ; p=0.24 ; 95 \%$ CI - $0.91 \mathrm{ml} / \mathrm{min} / 1.73 \mathrm{~m}^{2}, 3.62 \mathrm{ml} / \mathrm{min} / 1.73 \mathrm{~m}^{2}$; CKD stage $3: 9.2 \mathrm{ml} / \mathrm{min} / \mathrm{m}^{2} ; p=0.18 ; 95 \%$ 
Table 1 Baseline characteristics of study population (all patients treated for 8 weeks)

\begin{tabular}{|c|c|c|c|}
\hline & All non-cirrhotic & Naïve non-cirrhotic & $P / R$ experienced, non-cirrhotic \\
\hline$n$ & 505 & 374 & 131 \\
\hline Age (mean; years) & 49.7 & 48.4 & 53.4 \\
\hline Gender: male & $259(51.3 \%)$ & $187(50 \%)$ & $72(54.9 \%)$ \\
\hline \multicolumn{4}{|l|}{ Race } \\
\hline White & $423(83.8 \%)$ & $316(84.5 \%)$ & $104(79.4 \%)$ \\
\hline Asian & $7(11.3 \%)$ & $33(8.8 \%)$ & $24(18.3 \%)$ \\
\hline Black or African American & $17(3.4 \%)$ & $14(3.7 \%)$ & $3(2.3 \%)$ \\
\hline Others & $11(2.2 \%)$ & $11(2.9 \%)$ & - \\
\hline \multicolumn{4}{|l|}{ Fibrosis } \\
\hline F0-F1 & $418(82.8 \%)$ & $309(82.6 \%)$ & $109(83.2 \%)$ \\
\hline $\mathrm{F} 2$ & $30(5.9 \%)$ & $23(6.1 \%)$ & $7(5.3 \%)$ \\
\hline F3 & $57(11.3 \%)$ & $42(11.2 \%)$ & $15(11.5 \%)$ \\
\hline \multicolumn{4}{|l|}{ Genotype } \\
\hline 1 & $351(69.5 \%)$ & $217(58.0 \%)$ & $131(100 \%)$ \\
\hline 3 & $157(31.1 \%)$ & $157(42.0 \%)$ & - \\
\hline $\operatorname{BMI}(\geq 30)^{a}$ & $75(14.9 \%)$ & $57(15.2 \%)$ & $17(12.9 \%)$ \\
\hline Prior diabetes history: yes ${ }^{\mathrm{b}}$ & $17(3.4 \%)$ & $6(1.6 \%)$ & $11(8.3 \%)$ \\
\hline History of metabolic syndrome: yes ${ }^{\mathrm{c}}$ & $74(14.7 \%)$ & $58(15.5 \%)$ & $16(12.2 \%)$ \\
\hline Prior cardiovascular disease: yes ${ }^{\mathrm{d}}$ & $121(24.0 \%)$ & $70(18.7 \%)$ & $51(38.9 \%)$ \\
\hline \multicolumn{4}{|l|}{ HOMA-IR } \\
\hline$<2$ & $253(50.1 \%)$ & $188(50.3 \%)$ & $62(47.3 \%)$ \\
\hline$\geq 2$ & $169(33.5 \%)$ & $115(30.7 \%)$ & $54(41.2 \%)$ \\
\hline Missing & $86(17 \%)$ & $71(19 \%)$ & $15(11.5 \%)$ \\
\hline \multicolumn{4}{|l|}{ HCV history } \\
\hline Naïve-all & $374(74.1 \%)$ & $374(100 \%)$ & - \\
\hline $\mathrm{P} / \mathrm{R}$ experienced & $131(25.9 \%)$ & - & $131(100 \%)$ \\
\hline \multicolumn{4}{|l|}{ SVR12 } \\
\hline Yes & $497(98.4 \%)$ & $364(97.3 \%)$ & $130(99.2 \%)$ \\
\hline No & $7(1.4 \%)$ & $6(1.6 \%)$ & $1(0.8 \%)$ \\
\hline
\end{tabular}


Table 1 continued

\begin{tabular}{llll}
\hline & All non-cirrhotic & Naïve non-cirrhotic & P/R experienced, non-cirrhotic \\
\hline Missing & $4(0.8 \%)$ & $4(1.1 \%)$ \\
\hline
\end{tabular}

Sample includes patients without cirrhosis treated with G/P for 8 weeks across two phase 3 clinical trials (ENDURANCE-1 and ENDURANCE-3)

$H O M A-I R$ homeostatic model assessment-insulin resistance, $B M I$ body mass index, $P / R$ peg-interferon + ribavirin, $H C V$ hepatitis $\mathrm{C}$ virus, $S V R$ sustained virologic response

a Rest of the proportion represents patients with $\mathrm{BMI}<30$

b Rest of the proportion represent patients with no diabetes

c Rest of the proportion represent patients with no history of metabolic syndrome

${ }^{d}$ Rest of the proportion represent patients with no prior cardiovascular disease

$\mathrm{CI}-4.1 \mathrm{ml} / \mathrm{min} / 1.73 \mathrm{~m}^{2}, 22.4 \mathrm{ml} / \mathrm{min} / \mathrm{m}^{2}$ ) (Fig. 3a), (2) TN NC patients (Fig. 3b; Table S6), (3) the sample of 104 renally impaired patients with stage 4 and 5 CKD enrolled in the EXPEDITION-4 trial (stages 4 and $5:-0.3 \mathrm{ml} / \mathrm{min} /$ $1.73 \mathrm{~m}^{2 ;} \quad p=0.52 ; 95 \%$ CI $-1.3 \mathrm{ml} / \mathrm{min} /$ $\mathbf{a}$

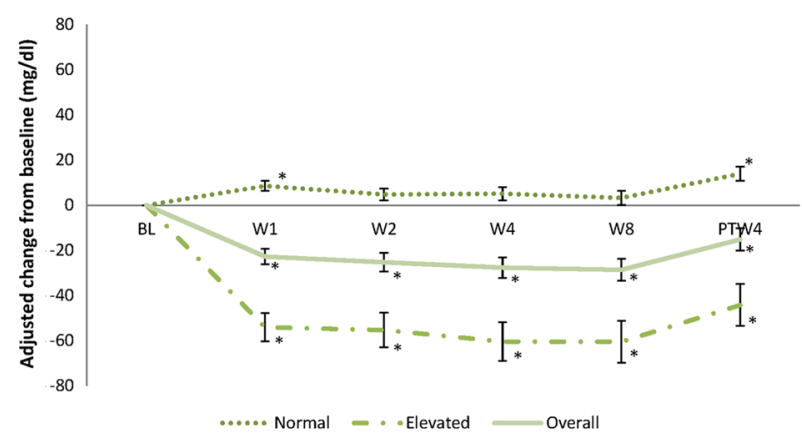

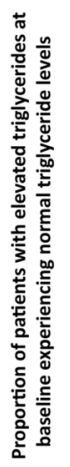

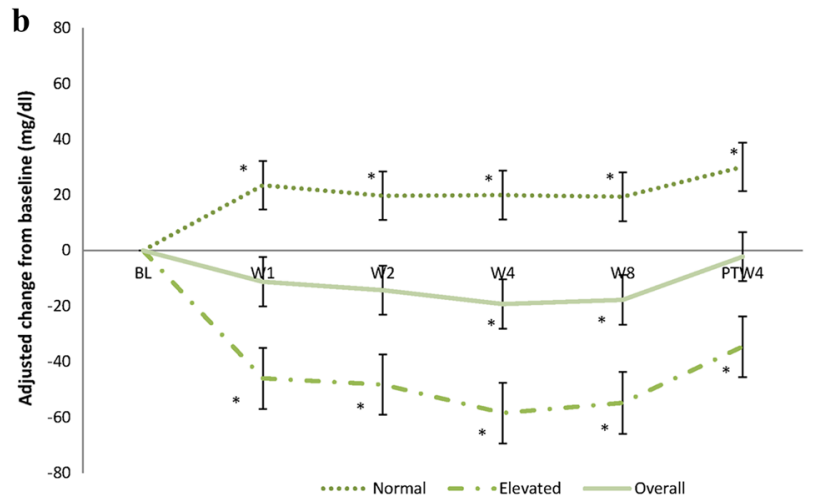

Fig. 1 a Predicted change in triglycerides from baseline: All patients treated with 8 weeks G/P. $H C V$ hepatitis C virus, $G / P$ glecaprevir and pibrentasvir; $B L$ baseline, $W$ week, PTW post-treatment week. Asterisk represents statistically significant change from baseline. Errors bars represent standard errors. b Predicted change in triglycerides from baseline: Treatment-naïve non-cirrhotic HCV patients treated with 8 weeks $\mathrm{G} / \mathrm{P}$. $H C V$ hepatitis $\mathrm{C}$ virus, $G / P$ glecaprevir and pibrentasvir, $B L$ baseline, $W$ week,
PTW post-treatment week. Asterisk represents statistically significant change from baseline. Errors bars represent standard errors. c Proportion of elevated triglycerides patients at BL experiencing normal in TGL levels at each time point on being treated for $\mathrm{HCV}$ post-treatment. $B L$ baseline, $H C V$ hepatitis $\mathrm{C}$ virus, $W$ week, EOT end of treatment, $P T W$ post-treatment week, $T N$ treatment naïve, $N C$ non-cirrhotic, $G / P$ glecaprevir and pibrentasvir 

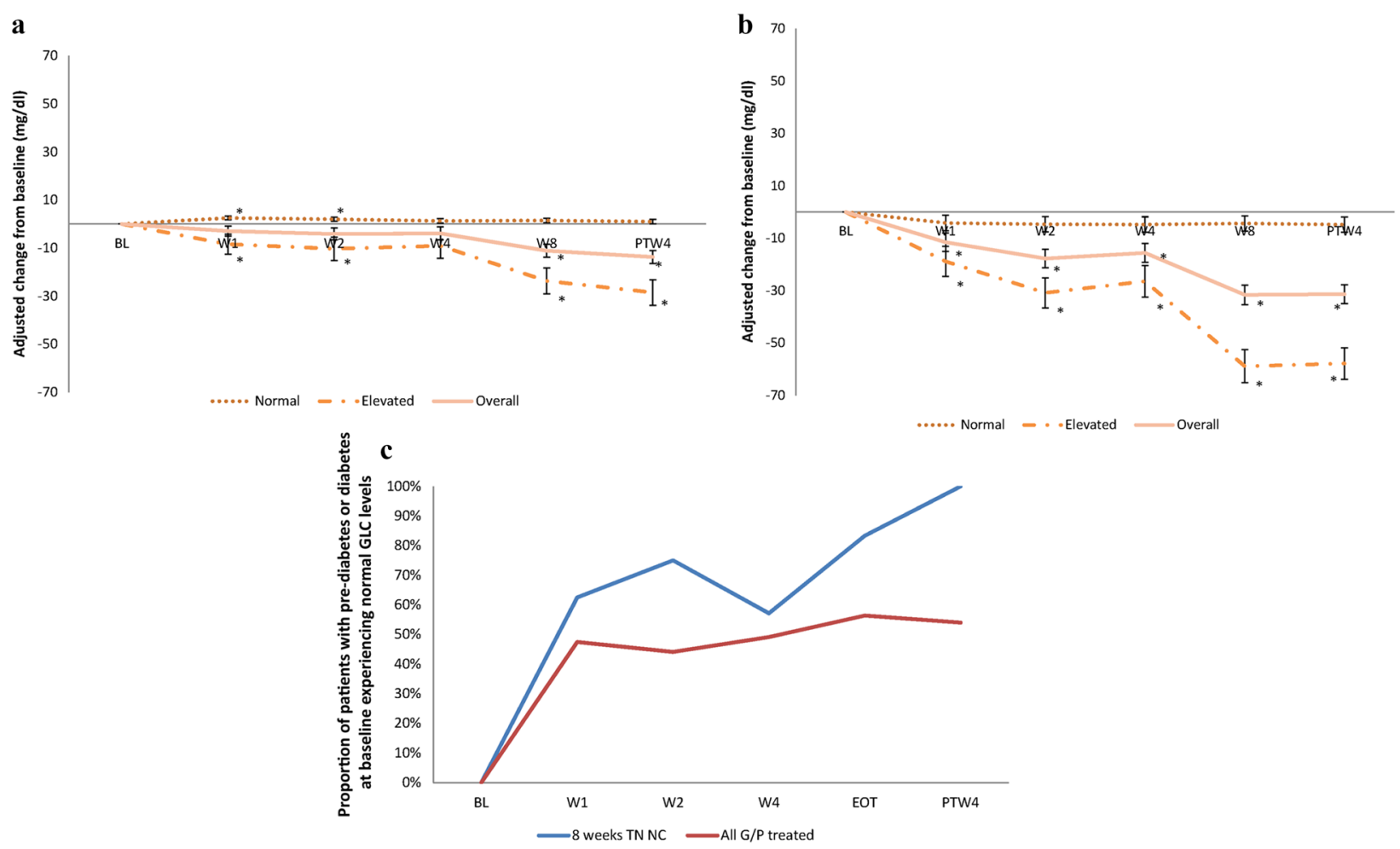

Fig. 2 a Predicted change in glucose from baseline: All patients treated with 8 weeks G/P. $H C V$ hepatitis $\mathrm{C}$ virus, $G / P$ glecaprevir and pibrentasvir, $B L$ baseline, $W$ week, $P T W$ post-treatment week. Asterisk represents statistically significant change from baseline. Errors bars represent standard errors. b Predicted change in glucose from baseline: Treatment-naïve non-cirrhotic $\mathrm{HCV}$ patients treated with 8 weeks $\mathrm{G} / \mathrm{P}$. $H C V$ hepatitis $\mathrm{C}$ virus, $G / P$ glecaprevir and pibrentasvir, $B L$ baseline, $W$ week, $P T W$

$1.73 \mathrm{~m}^{2}, \quad 0.65 \mathrm{ml} / \mathrm{min} / 1.73 \mathrm{~m}^{2}$ ) (Fig. $3 \mathrm{c}$ ), and (4) the pooled sample of patients treated for 8 or 12 weeks regardless of treatment history and cirrhosis status (Figure S3; Table S5c). However, patients with stage $1 \mathrm{CKD}$ had a significant decrease of $6.5 \mathrm{ml} / \mathrm{min} / 1.73 \mathrm{~m}^{2} \quad(p<0.001$; $95 \% \mathrm{CI}-8.9 \mathrm{ml} / \mathrm{min} / 1.73 \mathrm{~m}^{2},-4.1 \mathrm{ml} / \mathrm{min} /$ $1.73 \mathrm{~m}^{2}$ ) (Fig. 3a). Of the patients with baseline eGFR levels below $90 \mathrm{ml} / \mathrm{min} / 1.73 \mathrm{~m}^{2}, 14 \%$ had eGFR levels above $90 \mathrm{ml} / \mathrm{min} / 1.73 \mathrm{~m}^{2}$ and $27 \%$ experienced eGFR improvements of at least $10 \%$ by end of treatment (same proportions for TN NC) (Fig. 3d). post-treatment week. Asterisk represents statistically significant change from baseline. Errors bars represent standard errors. c Proportion of pre-diabetic or diabetic patients experiencing normal glucose levels at each time point on being treated for $\mathrm{HCV}$. $H C V$ hepatitis $\mathrm{C}$ virus, $G L C$ glucose, $B L$ baseline, $W$ week, EOT end of treatment, $P T W$ post-treatment week, $T N$ treatment-naïve, $N C$ noncirrhotic, $G / P$ glecaprevir and pibrentasvir

\section{DISCUSSION}

This analysis shows that treatment with G/P for 8 or 12 weeks is associated with significant improvements in EHM biomarkers for cardiovascular and metabolic EHMs and stable kidney function in patients with CKD stages 2-5. Consistent with previous literature [19], the benefits of treatment appeared to be greatest for patients with more severe baseline EHM markers, and these benefits were observed irrespective of treatment history and cirrhosis status. Prior studies have associated male gender and age at time of infection to be related to fibrosis progression [32], as well as viral factor (e.g., 

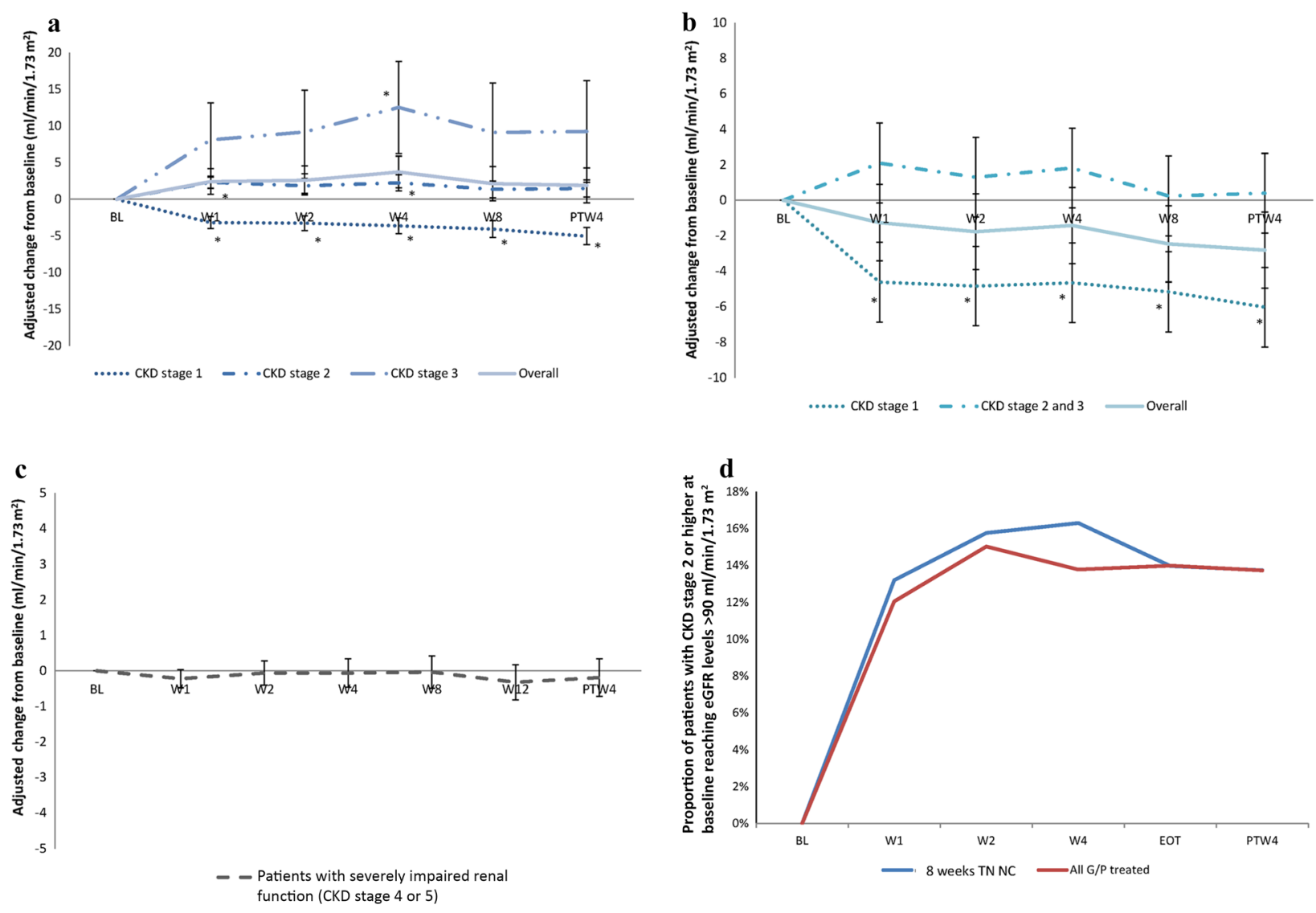

Fig. 3 a Predicted change in eGFR from baseline: all patients treated with 8 weeks G/P. eGFR estimated glomerular filtration rate, $H C V$ hepatitis $\mathrm{C}$ virus, $G / P$ glecaprevir and pibrentasvir, $B L$ baseline, $W$ week, $P T W$ post-treatment week, $C K D$ chronic kidney disease. Asterisk represents statistically significant change from baseline. Errors bars are standard errors. b Predicted change in eGFR from baseline: treatment-naïe non-cirrhotic HCV patients treated with 8 weeks G/P. eGFR estimated glomerular filtration rate, $H C V$ hepatitis $\mathrm{C}$ virus, $G / P$ glecaprevir and pibrentasvir, $B L$ baseline, $W$ week, $P T W$ post-treatment week, $C K D$ chronic kidney disease. Asterisk represents statistically significant change from baseline. Errors bars represent standard errors. c Predicted eGFR

genotype 3) [33]. The current study showed a greater proportion of patients with higher fibrosis stages had worsened EHM-related biomarkers at baseline, suggesting that, as liver fibrosis progresses, EHMs may worsen. Although significant disparities in access to DAA therapy for the non-cirrhotic patients persist, treatment in early stages of liver fibrosis

change from baseline: overall HCV patients with impaired renal function (CKD stages 4 and 5) and treated with G/P. eGFR estimated glomerular filtration rate, $H C V$ hepatitis C virus; CKD: chronic kidney disease, $G / P$ glecaprevir and pibrentasvir, $B L$ baseline, $W$ week, $P T W$ post-treatment week. d Proportion of CKD stage 2 or higher patients experiencing normal eGFR levels at each time point on being treated for HCV. CKD chronic kidney disease, $e G F R$ estimated glomerular filtration rate, $H C V$ hepatitis $\mathrm{C}$ virus, $T N$ treatment-naïve, $N C$ noncirrhotic, $B L$ baseline, $W$ week, $E O T$ end of treatment, $P T W$ post-treatment week, $G / P$ glecaprevir and pibrentasvir

may bring important extrahepatic benefits and before severe hepatic complications occur.

\section{Cardiovascular EHMs}

Elevated serum triglycerides are a known risk factor for coronary heart disease and long-term all-cause mortality [23, 24]. The mean 
decrement in triglycerides after 8 weeks of treatment with G/P was $28.6 \mathrm{mg} / \mathrm{dl}$ overall, and $60.4 \mathrm{mg} / \mathrm{dl}$ for patients with elevated baseline triglycerides. As a result, $61 \%$ of patients with elevated baseline triglycerides had normal levels lower than $175 \mathrm{mg} / \mathrm{dl}$ by end of treatment. If these observed improvements are sustained over time, G/P treatment may result in longterm benefits in cardiovascular outcomes.

\section{Metabolic EHMs}

Non-fasting blood glucose levels greater than $140 \mathrm{mg} / \mathrm{dl}$ have been associated with cardiovascular and macrovascular risks [34]. For this reason, the American College of Endocrinology guidelines recommend a glycemic control target of $<140 \mathrm{mg} / \mathrm{dl}$ [34]. In our analysis, the overall mean decrease in serum glucose levels at the end of 8 weeks of $\mathrm{G} / \mathrm{P}$ treatment was $11.2 \mathrm{mg} / \mathrm{dl}$, and $23.7 \mathrm{mg} / \mathrm{dl}$ in patients with prediabetes or diabetes, respectively. These declines in glucose resulted in nearly $56 \%$ of patients with baseline elevated glucose $(>140 \mathrm{mg} / \mathrm{dl})$ achieving glycemic control target by end of treatment.

\section{Renal EHM}

Our analysis revealed no significant renal function impairment with $\mathrm{G} / \mathrm{P}$ treatment overall. This finding was in line with those of previous studies of sofosbuvir-free DAAs [21], but it contrasted with evidence observed for sofosbuvir-containing regimens [35-37]. In a metaanalysis including 35 cohorts of patients from a CKD prognosis consortium, the adjusted HR of all-cause mortality and end-stage renal disease (ESRD) remained mostly unchanged in patients whose eGFR increased or decreased by $10 \%$ or less compared with patients with stable eGFR, but increased when eGFR decreased by more than $10 \%$. Furthermore, patients whose eGFR increased by more than $10 \%$ had a lower risk of progression to ESRD [27]. In our analysis, nearly $70 \%$ of patients who received $\mathrm{G} / \mathrm{P}$ for 8 weeks had stable or improved eGFR by end of treatment, and 28\% had eGFR improvements greater than $10 \%$. If these observed effects persist, treatment with G/P may decrease the risk of developing ESRD and all-cause mortality in the long term.

The mechanism of improvement in EHMs associated with antiviral therapy remains to be established but most likely involves multiple pathways. It seems reasonable that the mechanism of action involves reduction of inflammation because chronic HCV infection causes liver inflammation; however, the molecular pathways involved in HCV-induced liver inflammation are not well understood. Possible complex pathways include direct viral effects and indirect mechanisms involving cytokine pathways, oxidative stress, and steatosis induction [38]. Some pathways may be more specific to the disorder in question: for example, HCV infection modulates normal cellular gene expression and interferes with insulin signaling pathways, resulting in insulin resistance [39]. More studies are needed to elucidate the molecular mechanism of action of antiviral therapy on hepatic and extrahepatic HCV-related disease.

It is necessary to interpret our findings within certain limitations. First, the parameters selected as surrogates for extrahepatic disease were selected in a post hoc manner because they were measured in clinical trials. If de novo trials were conducted, different tests and biomarkers could have been selected for EHM measurement. For example, instead of fasting triglycerides alone, a complete fasting lipid panel could be used to assess cardiovascular risk. Also, serial HOMA-IR calculations would more precisely measure changes in glucose metabolism; and serial urine collection would result in more detailed documentation of treatment effects on kidney disease. Next, because the analysis included only patients enrolled in clinical trials, these results may not be reflected in the overall population; additional research may be needed to confirm these results in the real world. Although our analyses, stratified by baseline EHM severity, did not differentiate between patients who did or did not achieve SVR, antiviral efficacy probably plays a substantial role in improving EHM biomarkers because the overall SVR rate in the study sample exceeded $98 \%$. Due to lack of data during the post 
treatment period, the current analyses demonstrated effect of treatment only during treatment period and at 4 weeks post treatment. The fact that our results are reported only out to 4 weeks post-treatment is mitigated by studies demonstrating that SVR4 and SVR12 are highly concordant with SVR14 with high positive (> 97\%) and negative (> 94\%) predictive values [40], and by prior analyses of sofosbuvir-free DAAs suggesting that EHM improvements may persist for at least 1 year post treatment [21]. Although unlikely, the lack of a placebo group in this study does not allow us to rule out the possibility that better control of glucose and lipid levels may have resulted from increased adherence to maintenance medications as patients began HCV therapy. Results may also be confounded by unobservable factors (e.g., other comorbidities or concomitant medications) not gathered in the database. However, in a real-world study, concomitant medications did not significantly predict EHM clinical outcomes in the presence of antiviral treatment [15]. Furthermore, a post hoc study of clinical trial data from patients randomly assigned to $\mathrm{HCV}$ treatment or placebo also demonstrated favorable effects of treatment on EHM outcomes [21]. Finally, it should be noted that some patients included in our analysis did not receive an approved regimen, as indicated in the current product label of G/P.

In spite of its limitations, this analysis adds to the knowledge of the extrahepatic benefits of HCV treatment with pan-genotypic, short-duration, IFN- and sofosbuvir-free DAAs.

\section{CONCLUSION}

Treatment with G/P for as short as 8 weeks showed improved glucose and triglyceride levels by post-treatment week 4 irrespective of treatment history and cirrhosis status. These benefits were especially pronounced in patients with elevated triglycerides, pre-diabetes and diabetes at baseline. Treatment with $\mathrm{G} / \mathrm{P}$ also resulted in stable eGFR function in both during and post-treatment periods. Future studies are needed to determine whether these effects are maintained over longer periods of time.

\section{ACKNOWLEDGEMENTS}

Funding. The current work was supported by AbbVie Inc. Design and study conduct for the study was approved by AbbVie Inc. AbbVie Inc. participated in the interpretation of data and review and approval of the manuscript. Funding for publication charges was provided by AbbVie Inc. All authors had full access to all of the data in this study and take complete responsibility for the integrity of the data and accuracy of the data analysis.

Editorial Assistance. Editorial assistance, funded by AbbVie, was provided by Tom Owen (Fishawack Facilitate Ltd).

Authorship. All named authors meet the International Committee of Medical Journal Editors (ICMJE) criteria for authorship for this article, take responsibility for the integrity of the work and have given their approval for this version to be published.

Disclosures. Tram T. Tran: Received consulting, advisor/speaker fees, and research grants from Gilead Sciences, Bristol-Myers Squibb, and AbbVie. At the time of the study, Tram T. Tran was employed by Cedars-Sinai Medical Center. Tram T. Tran's current affiliation is Gilead Sciences, Foster City, CA, USA. Darshan Mehta: Financially supported for graduate research work by AbbVie as a part of a fellowship agreement between AbbVie and University of Southern California (USC). Federico Mensa is an employee of AbbVie Inc and may own stocks and/or options of the company. Caroline Park is an employee of AbbVie Inc and may own stocks and/or options of the company. Yanjun Bao is an employee of AbbVie Inc and may own stocks and/or options of the company. Yuri Sanchez Gonzalez is an employee of AbbVie Inc and may own stocks and/or options of the company.

Compliance with Ethics Guidelines. This analysis was conducted based on biomarker data collected in previously conducted studies and did not involve any new studies with 
human or animal subjects performed by any of the authors.

Data Availability. The datasets generated and analyzed during the current study are not publicly available for proprietary reasons but are available from the corresponding author on reasonable request.

Open Access. This article is distributed under the terms of the Creative Commons Attribution-NonCommercial 4.0 International License (http://creativecommons.org/licenses/ by-nc/4.0/), which permits any noncommercial use, distribution, and reproduction in any medium, provided you give appropriate credit to the original author(s) and the source, provide a link to the Creative Commons license, and indicate if changes were made.

\section{REFERENCES}

1. European Association for the Study of the Liver. EASL recommendations on treatment of hepatitis C 2018. J Hepatol. 2018;69:461-511.

2. Chen SL, Morgan TR. The natural history of hepatitis $\mathrm{C}$ virus (HCV) infection. Int $\mathrm{J}$ Med Sci. 2006;3:47-52.

3. Cacoub P, Gragnani L, Comarmond C, Zignego AL. Extrahepatic manifestations of chronic hepatitis C virus infection. Dig Liver Dis. 2014;46:S165-73.

4. Cacoub P, Poynard T, Ghillani P, et al. Extrahepatic manifestations of chronic hepatitis C. MULTIVIRC Group. Multidepartment Virus C. Arthritis Rheum. 1999;42:2204-12.

5. Cacoub P, Comarmond C, Domont F, Savey L, Desbois AC, Saadoun D. Extrahepatic manifestations of chronic hepatitis $\mathrm{C}$ virus infection. Ther Adv Infect Dis. 2016;3:3-14.

6. Mahale P, Sturgis EM, Tweardy DJ, Ariza-Heredia EJ, Torres HA. Association between hepatitis $\mathrm{C}$ virus and head and neck cancers. J Natl Cancer Inst. 2016;108:djw035.

7. Voulgaris T, Sevastianos VA. Atherosclerosis as extrahepatic manifestation of chronic infection with hepatitis $\mathrm{C}$ virus. Hepat Res Treat. 2016;2016:7629318.
8. Gill K, Ghazinian H, Manch R, Gish R. Hepatitis C virus as a systemic disease: reaching beyond the liver. Hepatol Int. 2016;10:415-23.

9. Moorman AC, Tong X, Spradling PR, et al. Prevalence of renal impairment and associated conditions among HCV-infected persons in the Chronic Hepatitis Cohort Study (CHeCS). Dig Dis Sci. 2016;61:2087-93.

10. van der Meer AJ, Veldt BJ, Feld JJ, et al. Association between sustained virological response and allcause mortality among patients with chronic hepatitis $\mathrm{C}$ and advanced hepatic fibrosis. JAMA. 2012;308:2584-93.

11. Morgan RL, Baack B, Smith BD, Yartel A, Pitasi M, Falck-Ytter Y. Eradication of hepatitis $\mathrm{C}$ virus infection and the development of hepatocellular carcinoma: a meta-analysis of observational studies. Ann Intern Med. 2013;158:329-37.

12. Berenguer J, Alvarez-Pellicer J, Martin PM, et al. Sustained virological response to interferon plus ribavirin reduces liver-related complications and mortality in patients coinfected with human immunodeficiency virus and hepatitis $\mathrm{C}$ virus. Hepatology. 2009;50:407-13.

13. Nahon P, Bourcier V, Layese R, et al. Eradication of hepatitis $C$ virus infection in patients with cirrhosis reduces risk of liver and non-liver complications. Gastroenterology. 2016;152:142-56.

14. Hsu YC, Lin JT, Ho HJ, et al. Antiviral treatment for hepatitis $\mathrm{C}$ virus infection is associated with improved renal and cardiovascular outcomes in diabetic patients. Hepatology. 2014;59:1293-302.

15. Hsu YC, Ho HJ, Huang YT, et al. Association between antiviral treatment and extrahepatic outcomes in patients with hepatitis $\mathrm{C}$ virus infection. Gut. 2015;64:495-503.

16. Mahale P, Angels EA, Li R, et al. The effect of sustained virological response on the risk of extrahepatic manifestations of hepatitis $\mathrm{C}$ virus infection. Gut. 2018;67:553-61.

17. Cacoub P, Desbois AC, Comarmond C, Saadoun D. Impact of sustained virological response on the extrahepatic manifestations of chronic hepatitis C: a meta-analysis. Gut. 2018. https://doi.org/10. 1136/gutjnl-2018-316234 (epub ahead of print).

18. Chattwal J. Direct acting antivirals for hepatitis c treatment: effectiveness versus cost-effectiveness. Futur Virol. 2015;10:929-32.

19. Mehta DA, Cohen E, Charafeddine M, et al. Effect of hepatitis $\mathrm{C}$ treatment with ombitasvir/paritaprevir/ $\mathrm{R}+$ dasabuvir on renal, cardiovascular and 
metabolic extrahepatic manifestations: a post hoc analysis of phase 3 clinical trials. Infect Dis Ther. 2017;6:515-29.

20. Singer AW, Osinusi A, Brainard DM, Chokkalingam AP. Risk of cardiovascular and cerebrovascular events in hepatitis $\mathrm{C}$ patients following completion of direct-acting antiviral therapy: a retrospective cohort study (abstract). J Hepatol. 2017;66(Suppl): S282-3.

21. Reau N, Vekeman F, Wu E, Bao Y, Gonzalez YS. Prevalence and economic burden of extrahepatic manifestations of hepatitis $\mathrm{C}$ virus are underestimated but can be improved with therapy. Hepatol Commun. 2017;1:439-52.

22. European Association for the Study of the Liver. EASL recommendations on treatment of hepatitis C 2018. J Hepatol. 2018;69:461-511.

23. Emerging Risk Factors Collaboration, Di Angelantonio E, Sarwar N, et al. Major lipids, apolipoproteins, and risk of vascular disease. JAMA. 2009;302: 1993-2000.

24. Klempfner R, Erez A, Sagit BZ, et al. Elevated triglyceride level is independently associated with increased all-cause mortality in patients with established coronary heart disease twenty-two-year follow-up of the Bezafibrate Infarction Prevention study and registry. Circ Cardiovasc Qual Outcomes. 2016;9:100-8.

25. American Diabetes Association. Report of the expert committee on the diagnosis and classification of diabetes mellitus. Diabetes Care. 1997;20:1183-97.

26. Goldberg RB, Mellies MJ, Sacks FM, et al. Cardiovascular events and their reduction with pravastatin in diabetic and glucose-intolerant myocardial infarction survivors with average cholesterol levels: subgroup analyses in the Cholesterol and Recurrent Events (CARE) trial. Circulation. 1998;98:2513-9.

27. Coresh J, Turin TC, Matsushita K, et al. Decline in estimated glomerular filtration rate and subsequent risk of end-stage renal disease and mortality. JAMA. 2014;311:2518-31.

28. Nordestgaard B, Langsted A, Mora S, et al. Fasting is not routinely required for determination of a lipid profile: clinical and laboratory implications including flagging at desirable concentration cutpoints-a joint consensus statement from the European Atherosclerosis Society and European Federation of Clinical Chemistry and Laboratory Medicine. Eur Heart J. 2016;37:1944-58.
29. American Diabetes Association. Classification and diagnosis of diabetes. Diabetes Care. 2016;39(Suppl. 1):S13-22.

30. Lamb EJ, Levey AS, Stevens PE. The Kidney Disease Improving Global Outcomes (KDIGO) guideline update for chronic kidney disease: evolution not revolution. Clin Chem. 2013;59:462-5.

31. Albert PS. Longitudinal data analysis (repeated measures) in clinical trials. Stat Med. 1999;18: 1707-32.

32. Marcellin P, Asselah T, Boyer N. Fibrosis and disease progression in hepatitis C. Hepatology. 2002;36(Suppl):S47-56.

33. Bochud P, Cai T, Overbeck T, et al. Genotype 3 is associated with accelerated fibrosis progression in chronic hepatitis C. J Hepatol. 2009;51:655-66.

34. American Diabetes Association. Classification and diagnosis of diabetes. Diabetes Care. 2015;38(Suppl): S8-16.

35. Almarzooqi S, Klair JS, Karkada JG, et al. Frequency of renal impairment in patients with hepatitis $\mathrm{C}$ infection treated with sofosbuvir based-antiviral regimens (abstract). Hepatology. 2015;62(Suppl): 141A.

36. Rosenblatt R, Mehta A, Wagner M, Kumar S. Baseline creatinine clearance is a predictor of worsening renal function while on $\mathrm{HCV}$ treatment with sofosbuvir-ledipasvir (abstract). J Hepatol. 2016;64: S819.

37. Carey I, Verma S, Mrzljak A, et al. Transient renal dysfunction during INF-free therapy in decompensated HCV cirrhosis patients (abstract). Hepatology. $2015 ; 62: 142 \mathrm{~A}$.

38. Zampino R, Marrone A, Restivo L, et al. Chronic HCV infection and inflammation: clinical impact on hepatic and extra-hepatic manifestations. World J Hepatol. 2013;5:528-40.

39. Bose SK, Ray R. Hepatitis C virus infection and insulin resistance. World J Diabetes. 2014;5:52-8.

40. Burgess SV, Hussaini T, Yoshida EM. Concordance of sustained virologic response at weeks 4,12 and 24 post-treatment of hepatitis $c$ in the era of new oral direct-acting antivirals: a concise review. Ann Hepatol. 2016;15:154-9. 